\title{
Stem modularity alone is not effective in reducing dislocation rate in hip revision surgery
}

\author{
Dario Regis • Andrea Sandri • Pietro Bartolozzi
}

Received: 28 July 2009/Accepted: 3 November 2009/Published online: 18 November 2009

(C) Springer-Verlag 2009

\begin{abstract}
Background Dislocation is a serious complication following total hip arthroplasty (THA). Femoral revision using monoblock components has been associated with high incidence of subsidence and dislocation. Advantages of modular stems in THA have long been debated. The aim of this retrospective study is to assess the capability of an uncemented modular stem in decreasing the incidence of early dislocation subsequent to revision THA.

Materials and methods We evaluated the dislocation rate during the first 2 years following revision surgery in two groups of patients who were treated by implantation of a cementless tapered femoral prosthesis; a standard-modularity stem (Wagner SL) and an increased-modularity stem (Profemur R) were used, respectively, in 66 hips (group I, 64 patients) and 102 hips (group II, 97 patients). Group I consisted of 47 females and 17 males with average age of 66 years (range 29-84 years). Group II included 60 females and 37 males with average age of 70 years (range 48-89 years).

Results Dislocation occurred in six hips $(9.1 \%)$ of group I and in seven hips $(6.8 \%)$ of group II $(P=0.401)$. Dislocations were observed early in both groups, except
\end{abstract}

D. Regis · A. Sandri · P. Bartolozzi

Department of Orthopaedic Surgery,

University School of Medicine, Verona, Italy

A. Sandri

e-mail: andrea.sandri@azosp.vr.it

P. Bartolozzi

e-mail: Pietro.Bartolozzi@univr.it

D. Regis $(\square)$

Istituto di Clinica Ortopedica e Traumatologica,

Policlinico GB Rossi, Piazzale LA Scuro 10,

37134 Verona, Italy

e-mail: regisdario@siot.it one hip in group II that dislocated 434 days postoperatively and required surgical reduction. All other dislocations were treated by closed reduction. No recurrence was observed.

Conclusions The use of an increased-modularity revision stem alone did not prove to be effective in reducing the risk of postoperative dislocation.

Keywords Dislocation - Femoral revision .

Modular stem · Tapered stem · Revision hip arthroplasty

\section{Introduction}

Dislocation is an important local complication after total hip arthroplasty (THA), with a considerably higher incidence in revision surgery $[1,2]$.

Among risk factors associated with hip dislocation, femoral and/or acetabular component malposition and poor restoration of appropriate muscular tension play a primary role [1-3].

In femoral revision, the use of a fluted, tapered stem developed by Wagner [4, 5] allowed successful treatment even in cases complicated by extensive proximal bone loss, thanks to adequate distal fixation. The Wagner revision stem joined regularly the occurrence of periprosthetic new bone formation [5-15] but exhibited two major drawbacks: the risk of stem subsidence [6, 7, 9-11, 13] and high incidence of dislocation, as much as $20 \%$ in some case series $[6,7,9,11-14]$.

In revision surgery, femoral bone loss is highly variable, and restoration of the femoral head center at the correct length, offset, and anteversion with soft tissue balance may be difficult to achieve [9]. Consequently, increased-modularity cementless stems have been developed to solve 
these issues; they consist of several parts that can be assembled to change the orientation of every component and correct the version, length, and offset to promote proper soft tissue tension [16-19]. The aim of this study is to evaluate retrospectively if the early dislocation rate after revision THA could be reduced using an uncemented increased-modularity revision stem.

\section{Materials and methods}

Between September 1992 and April 2007, 171 THA revisions in 164 patients were performed using in all cases an uncemented tapered stem. The main reason for operation was aseptic loosening. Other indications included periprosthetic fracture, second-stage surgery following infection, and femoral stem breakage. No case of prosthetic instability was treated. During the first period, from September 1992 to March 1998, a standard-modularity femoral component (Wagner SL, Sulzer Orthopedics Ltd., Winterthur, Switzerland) was used in 68 hips in 66 patients (two bilateral implants). Later, from May 1995 to April 2007, an increased-modularity stem (Profemur R, Wright Medical Technology, Arlington, TN) was used in 103 hips in 98 patients (five bilateral implants).

The Wagner SL stem is available in four sizes and is conically shaped in the distal part, with eight longitudinal antirotational ribs. Three different head lengths are available; a 32-mm-diameter femoral head was used in all cases. Profemur $\mathrm{R}$ is a modular prosthesis that consists of a tapered diaphyseal stem with cutting flutes and a rough surface, and a metaphyseal double-cone body, connected via a Morse taper and a securing screw. The modularity is completed by the availability of three different length heads and interchangeable necks with different length and version, which allow different offset and version to be obtained; in all cases a 28mm-diameter femoral head was implanted.

Revision surgery was performed with the patient in supine position under general anesthesia; an anterolateral approach without osteotomy of the greater trochanter was carried out. After removing the prosthesis and accurately cleaning the bone surfaces, the acetabular cup was revised first, followed by the femoral stem.

All patients underwent a rehabilitation programme with isometric muscle training and exercises of supported active and passive motion of the limb from the second day after surgery. Ambulation with two crutches started after 1 week, allowing partial weight bearing after 1 month and unrestrained walking 4-6 months after surgery.

Clinical data collected on all patients included presence or absence of dislocation and time to dislocation. Checks for dislocation continued up to 2 years following surgery; after this period, dislocation can be considered infrequent [20]. All
Table 1 Patient data

\begin{tabular}{llll}
\hline & $\begin{array}{l}\text { Males } \\
\text { (hips) }\end{array}$ & $\begin{array}{l}\text { Females } \\
\text { (hips) }\end{array}$ & $\begin{array}{l}\text { Age } \\
\text { (years) }\end{array}$ \\
\hline Group I & 18 & 48 & $66.14 \pm 13.01$ \\
Group II & 37 & 65 & $70.70 \pm 9.01$ \\
Tests of intergroup difference & $P=0.295^{\dagger}$ & \\
${ }^{*}$ Values are mean \pm standard deviation & & \\
${ }^{\dagger}$ Chi-square test &
\end{tabular}

patients gave informed consent to be included in the study, and the study was authorized by the local ethical committee and was performed in accordance with the ethical standards of the 1964 Declaration of Helsinki as revised in 2000.

In the Wagner and Profemur groups, respectively, two and one cases were excluded, because dislocation occurred with stem subsidence $>10 \mathrm{~mm}$ [13]. Finally, 168 hips in 161 patients were available. This study consisted of a first group (group I) treated with a Wagner standard-modularity prosthesis, including 66 hips in 64 patients $(18$ males and 48 females) with average age of 66 years (range 2984 years), and a second group (group II) of 102 revisions in 97 patients (65 males and 37 females) with average age of 70 years (range 48-89 years) who received a Profemur R increased-modularity stem (Table 1). Revision surgery included acetabular replacement in all but three and two cases in group I and II, respectively.

Intergroup chi-square testing was used to distinguish statistically between study data as regards patient gender distribution. Fisher's exact probability test was used to compare intergroup hip dislocation rate and to distinguish any statistically significant difference that may have existed as regards early THA dislocation rate. A $P$ value $\leq 0.05$ was considered significant.

\section{Results}

Postoperative hip dislocation occurred for 6 (9.1\%) of 66 hips in which a standard-modularity stem was used (group I). The postoperative course of the patients who received an increased-modularity prosthesis (group II) was complicated by dislocation in $7(6.8 \%)$ of 102 hips $(P=0,401 ;$ Table 2$)$. In both groups dislocation was

Table 2 Dislocation rate

\begin{tabular}{lll}
\hline & $\begin{array}{l}\text { Dislocations } \\
(\%)\end{array}$ & $\begin{array}{l}\text { Nondislocations } \\
(\%)\end{array}$ \\
\hline Group I & $6(9.1 \%)$ & $60(90.9 \%)$ \\
Group II & $7(6.8 \%)$ & $95(93.2 \%)$ \\
Tests of intergroup difference & $P=0.401^{\dagger}$ & \\
\hline
\end{tabular}

\footnotetext{
† Fisher's exact probability test
} 
treated with closed reduction (except one case that required open reduction) and immobilization by means of orthopedic brace for 1 month. Dislocation was observed early in the postoperative, from 12 to 24 days after the operation, in group I. Even in group II this complication occurred early, from 14 to 29 days postoperatively, except one hip that dislocated 434 days after operation and required open reduction. No recurrent dislocation was observed.

\section{Discussion}

Dislocation is a troublesome and disabling complication, occurring in $1-3 \%$ after primary THA and in $7-10 \%$ after revision hip surgery [1,2]. Alberton and coworkers [3] evaluated risk factors leading to hip instability and stated that dislocation after revision arthroplasty has different causes than those after primary THA.

The higher dislocation rate of revision THA may be related to soft tissue deficiencies. Boucher et al. [21] evaluated acetabular polyethylene liner exchange in patients without previous dislocation. A postoperative dislocation rate of $25 \%$ was found, demonstrating that reestablishing adequate soft tissue tension and range of motion without impingement was essential in avoiding an unstable THA. Re-establishment of femoral offset in total hip replacement restores biomechanics of the hip and soft tissue balance, and may reduce dislocation risk. Procenca and Cabral [22] used two monoblock taper stems with different offset, the Wagner stem $\left(145^{\circ} \mathrm{CCD}\right.$ angle) and the Conelock stem $\left(135^{\circ} \mathrm{CCD}\right.$ angle), reporting a decrease of dislocation rate from $12 \%$ to $3 \%$, respectively.

Moreover, morphologic changes of the proximal femur make revision THA a demanding procedure. Monoblock fluted and tapered stems provide stable axial fixation in the distal femur and excellent rotational stability, promoting spontaneous formation of new bone at the site of the defect $[6,7,9,11-15]$. However, the main problem is related to lack of versatility in terms of version and offset. Weber et al. [9] reported five dislocations in 40 revision hip arthroplasties using the Wagner stem and suggested two main reasons for these dislocations: lack of active soft tissue tension related to abductor muscle atrophy, and low offset of the prosthesis, which results in impingement of the trochanteric region into the pelvis. Several studies involving the use of an increased-modularity stem demonstrated the possibility to adjust leg length, offset, neck length, and version during revision surgery [17-19]. Kopec et al. [23] examined 21 THA revisions using a modular stem and, through a computer-aided design (CAD) system reconstruction, the range of femoral component positioning was evaluated. Only in one case (5\%) was the stem orientation similar to that of a nonmodular prosthesis,
Table 3 Dislocation rate with standard-modularity tapered stem

\begin{tabular}{llcc}
\hline Reference & Stem & $\begin{array}{l}\text { No. of } \\
\text { hips }\end{array}$ & $\begin{array}{l}\text { Dislocations } \\
(\%)\end{array}$ \\
\hline Bartolozzi et al. [6] & Wagner SL & 50 & 12 \\
Wagner and Wagner [5] & Wagner SL & 69 & 2.9 \\
Isacson et al. [7] & Wagner SL & 43 & 20.9 \\
Bircher et al. [8] & Wagner SL & 99 & 4.1 \\
Boisgard et al. [14] & Wagner SL & 52 & 7.8 \\
Weber et al. [9] & Wagner SL & 40 & 12.5 \\
Ferruzzi et al. [10] & Wagner SL & 350 & 4 \\
Böhm and Bischel [11] & Wagner SL & 129 & 5.4 \\
Gutiérrez del Alamo et al. [12] & Wagner SL & 79 & 13.9 \\
Mantelos et al. [15] & Wagner SL & 82 & 2.1 \\
\hline
\end{tabular}

indicating that neck and metaphysis version often needed to be established independently from stem placement.

In our comparative series, the rate of dislocation decreased from $9.1 \%$ in the group of patients who received a standard-modularity stem to $6.8 \%$ after the introduction of a modular implant, even if the result was not statistically significant $(P=0.401)$. Our data are similar to those of several clinical studies, with a dislocation rate in revision surgery ranging from $2.1 \%$ to $20.9 \%$ with standard monoblock stems and from $1.3 \%$ to $11.3 \%$ with increasedmodularity stems (Tables 3, 4). Furthermore, to our knowledge no case series is available reporting the dislocation rate through a direct comparison between monoblock and modular stems.

A preliminary evaluation of the dislocation rate that we observed with the same models of tapered stems (monoblock and increased modularity) was already reported [24]. Though the difference between the two groups of patients was not significant, the given trend led us to assume that modularity could decrease the rate of dislocation in revision hip surgery. However, based on the data that we finally obtained when performing a longer-term assessment, we actually consider that stem modularity alone is not helpful.

Table 4 Dislocation rate with increased-modularity tapered stem

\begin{tabular}{llcc}
\hline Reference & Stem & No. of hips & Dislocations (\%) \\
\hline Wirtz et al. [27] & MRP-Titan & 142 & 11.3 \\
Kwong et al. [34] & MP & 143 & 2.1 \\
Park et al. [36] & Lima-Lto & 62 & 5 \\
Kang et al. [17] & ZMR taper & 47 & 2.1 \\
Rodriguez et al. [19] & MP & 97 & 10.3 \\
Köster et al. [37] & Profemur-R & 73 & 1.3 \\
Ovesen et al. [38] & ZMR taper & 125 & 6.4 \\
\hline
\end{tabular}


The modular prosthesis we used, Profemur R, in addition to the availability of proximal and distal parts and heads, offers the peculiarity of an interchangeable neck, which means it is possible to modify the final length and orientation of the prosthesis. The use of a proximal modular prosthesis at the time of further operations greatly simplifies strategies for revision surgery since the modular components can be removed, facilitating exposure and allowing for changes in offset, leg length, and anteversion without the need for revising the distal femoral component [25-27]. Wirtz et al. [28] presented early results of 142 uncemented femoral stem revisions using the modular MRP-Titan system, reporting five cases of recurrent dislocation $(3.5 \%)$ which were successfully managed by modifying the angle of anteversion without changing out the distal portion of the stem.

Among the possible drawbacks of modularity is the larger number of parts, which could result in risk of fracture, dissociation, and mismatching of components and greater production of metallic debris due to friction of the components $[29,30]$. Laboratory tests proved that modular prosthesis can be considered a reliable solution when several parts of the implant are correctly coupled [31]. This is supported as more and more clinical medium-term outcomes document the validity of modularity in femoral revision, with high survival rates [32-39].

Certainly, the present study has a series of weaknesses. It was a retrospective analysis, and patients were not randomized. The number of cases in each group was small and not homogeneous in terms of age and especially gender (with a higher rate of females in group I). Furthermore, we did not evaluate other well-known risk factors for dislocation, such as the number of surgeries, the type of approach, and the orientation of the acetabular component.

In conclusion, modularity provides the possibility to facilitate the intraoperative choice of the femoral version, length, and offset, independently of distal fixation. However, the use of an increased-modularity revision stem alone does not seem to be effective in reducing the risk of postoperative dislocation.

Conflict of interest statement The authors declare that they have no conflict of interest in connection with the submitted article.

\section{References}

1. Bourne RB, Mehin R (2004) The dislocating hip: what to do, what to do. J Arthroplasty 19(4 Suppl 1):111-114

2. Padgett DE, Warashina H (2004) The unstable total hip replacement. Clin Orthop Relat Res 420:72-79

3. Alberton GM, High WA, Morrey BF (2002) Dislocation after revision total hip artrhoplasty: an analysis of risk factors and treatment options. J Bone Joint Surg Am 84:1788-1792
4. Wagner H (1987) Revisionprosthese für das hüftegelenk bei schwerem knochenverlust. Orthopäde 16:295-300

5. Wagner M, Wagner H (1999) Der transfemorale zugang zur revision von hüftendoprothesen. Oper Orthop Traumatol 11:278295

6. Bartolozzi P, Regis D, Luzi CA, Schepis V (1998) Osteolisi periprotesica d'anca: risultati a medio termine della tecnica di ricostruzione con innesti ossei massivi acetabolari "armati" e stelo femorale ad ancoraggio distale con accesso transfemorale. Ital J Orthop Traumatol 24:269-284

7. Isacson J, Stark A, Wallensten R (2000) The Wagner revision prosthesis consistently restores femoral bone structure. Int Orthop 24:139-142

8. Bircher HP, Riede U, Lüem M, Ochsner PE (2001) Der wert der SL-Revisionsprosthese nach Wagner zur überbrückung großer femurdefekte. Technik und resultate. Orthopäde 30:294-303

9. Weber M, Hempfing A, Orler R, Ganz R (2002) Femoral revision using the Wagner stem: results at 2-9 years. Int Orthop 26:36-39

10. Ferruzzi A, Calderoni P, Gualtieri G (2003) Hip prosthesis revisions with LS stem: indications and results. Chir Organi Mov 88:285-289

11. Böhm P, Bischel O (2004) The use of tapered stems for femoral revision surgery. Clin Orthop Relat Res 420:148-159

12. Gutiérrez del Alamo J, Garcia-Cimbrelo E, Castellanos V, GilGaray E (2007) Radiographic bone regeneration and clinical outcome with the Wagner SL revision stem: a 5-year to 12-year follow-up study. J Arthroplasty 22:515-524

13. Kolstad K, Adalberth G, Mallmin H, Milbrink J, Sahlstedt B (1996) The Wagner revision stem for severe osteolysis. 31 hips followed for 1.5-5 years. Acta Orthop Scand 67:541-544

14. Boisgard S, Moreau PE, Tixier H, Levai JP (2001) Bone reconstruction, leg length discrepancy, and dislocation rate in 52 Wagner revision total hip arthroplasties at 44-month follow-up. Rev Chir Orthop Reparatrice Appar Mot 87:147-154

15. Mantelos G, Koulouvaris P, Kotsovolos H, Xenakis T (2008) Consistent new bone formation in 95 revisions: average 9-year follow-up. Orthopedics 31:654

16. Jones RE (2004) Modular revision stems in total hip arthroplasty. Clin Orthop Relat Res 420:142-147

17. Kang MN, Huddleston JI, Hwang K, Imrie S, Goodman SB (2008) Early outcome of a modular femoral component in revision total hip arthroplasty. J Arthroplasty 23:220-225

18. Higuera CA, Hanna G, Florjancik K, Allan DG, Robinson R, Barsoum WK (2006) The use of proximal fixed modular stems in revision of total hip arthroplasty. J Arthroplasty 21(4 Suppl 1):112-116

19. Rodriguez JA, Fada R, Murphy SB, Rasquinha VJ, Ranawat CS (2008) Two-year to five-year follow-up of femoral defects in femoral revision treated with the Link MP modular stem. J Arthroplasty. 2008 Oct 31 [Epub ahead of print]

20. Callaghan JJ, Heithoff BE, Goetz DD, Sullivan PM, Pedersen DR, Johnston RC (2001) Prevention of dislocation after hip arthroplasty: lessons from long-term followup. Clin Orthop Relat Res 393:157-162

21. Boucher HR, Lynch C, Young AM, Engh CA Jr, Engh C Sr (2003) Dislocation after polyethylene liner exchange in total hip arthroplasty. J Arthroplasty 18:654-657

22. Procenca A, Cabral R (2005) Revision of the femoral side in total hip replacement. Eur Instr Course Lect 7:143

23. Kopec MA, Pemberton A, Milbrandt JC, Allan DG (2009) Component version in modular total hip revision. Iowa Orthop J 29:5-10

24. Regis D, Furfaro V, Rizzo A, Soldà M, Corallo F (2005) La stabilità articolare nella revisione delle protesi d'anca: esperienza con stelo monoblocco e modulare. GIOT 31(Suppl 1):77-79 
25. Toomey SD, Hopper RH Jr, McAuley JP, Engh CA (2001) Modular component exchange for treatment of recurrent dislocation of a total hip replacement in selected patients. J Bone Joint Surg Am 83:1529-1533

26. Earll MD, Fehring TK, Griffin WL, Mason JB, McCoy T, Odum S (2002) Success rate of modular component exchange for the treatment of an unstable total hip arthroplasty. J Arthroplasty 17:864-869

27. Regis D, Modena M, Danesi G, Corallo F, Bartolozzi P (2003) Head-neck disassembly of an uncemented revision stem treated by addition of a proximal spacer. Acta Orthop Belg 69:463-466

28. Wirtz DC, Heller KD, Holzwarth U, Siebert C, Pitto RP, Zeiler G, Blencke BA, Forst R (2000) A modular femoral implant for uncemented stem revision in THR. Int Orthop 24:134-138

29. Barrack RL, Burke DW, Cook SD, Skinner HB, Harris WH (1993) Complications related to modularity of total hip components. J Bone Joint Surg Br 75:688-692

30. Bobyn JD, Tanzer M, Krygier JJ, Dujovne AR, Brooks CE (1994) Concerns with modularity in total hip arthroplasty. Clin Orthop Relat Res 298:27-36

31. Baleani M, Viceconti M, Walchholz K, Toni A (1997) Metallic wear debris in dual modular hip arthroplasty. Chir Organi Mov 82:231-238

32. Smith JA, Dunn HK, Manaster BJ (1997) Cementless femoral revision arthroplasty. 2- to 5-year results with a modular titanium alloy stem. J Arthroplasty 12:194-201
33. Christie MJ, DeBoer DK, Tingstad EM, Capps M, Brinson MF, Trick LW (2000) Clinical experience with a modular noncemented femoral component in revision total hip arthroplasty: 4to 7-year results. J Arthroplasty 15:840-848

34. Cameron HU (2003) Stem modularity is unnecessary in revision total hip arthroplasty: in opposition. J Arthroplasty 18(3 Suppl 1):101-103

35. Kwong LM, Miller AJ, Lubinus P (2003) A modular distal fixation option for proximal bone loss in revision total hip arthroplasty: a 2- to 6-year follow-up study. J Arthroplasty 18(3 Suppl 1):94-97

36. McCarthy JC, Lee J (2007) Complex revision total hip arthroplasty with modular stems at a mean of 14 years. Clin Orthop Relat Res 465:166-169

37. Park YS, Moon YW, Lim SJ (2007) Revision total hip arthroplasty using a fluted and tapered modular distal fixation stem with and without extended trochanteric osteotomy. J Arthroplasty 22:993-999

38. Köster G, Walde TA, Willert HG (2008) Five- to 10-year results using a noncemented modular revision stem without bone grafting. J Arthroplasty 23:964-970

39. Ovesen O, Emmeluth C, Hofbauer C, Overgaard S (2009) Revision total hip arthroplasty using a modular tapered stem with distal fixation: good short-term results in 125 revisions. J Arthroplasty [Epub ahead of print] 